\title{
Research on the Coordinated Development Strategy of Regional Science and Technology Finance
}

\author{
Fengxiang Jiang, Yi Xu, Runting Xiao, Changjun Du \\ Xi’an Peihua University, Xi’an Shaanxi, 710125
}

Keywords: regional; science and technology finance; Coordinated Development

\begin{abstract}
The paper puts forward an efficient financial market service model, establishes a multi-level capital market, builds a direct investment and financing platform, and forms an effective set of financial services under the framework of cooperative development, in view of the support of scientific and technological innovation in the financial service system, to improve the efficiency of investment and financing of technological innovation, support the design and application of innovative financial instruments, expand the sources of financing for technological innovation, and enhance the matching degree of investment and financing. At the same time, it can reduce the information asymmetry phenomenon in the process of technological innovation, effectively control the enterprise risk, and can produce the incentive and restraint function to the behavior of the investment and main financing body.
\end{abstract}

\section{Introduction}

The development of regional economy needs science and technology innovation to drive, regional science and technology innovation drive needs to be supported by science and technology finance, and the development of regional science and technology finance needs to be supported by science and technology innovation, in order to achieve regional economic growth, promote the knowledge level of regional economic development. This paper first studies the current situation and trend of science and technology finance development, then analyzes the existing models of regional science and technology finance cooperative development, and finally tries to explore the regional science and technology finance cooperative development strategy.

\section{The current situation and trend of science and technology finance}

\subsection{The current situation of science and technology finance}

The development of science and technology finance in our country is mainly embodied in the six major forms, including internet payment, network borrowing, crowd funding, internet fund sales, internet insurance and internet consumption finance at present. To varying degrees, they have brought enormous convenience to the people's lives, especially Internet fund sales, which rely on the Internet, big data and cloud computing technologies. Insurance and other business have rapid development because of consumer investment and financial management to provide accurate and reliable reference data in recent years. The total revenue of Chinese financial technology enterprises reached 654.14 billion Yuan, a 55.2\% year-on-year growth rate. Visible science and technology finance in our country's development heat, the market prospect is broad. The improvement of relevant government support means and relevant laws and regulations provides policy guarantee for the development of science and technology finance. The government has guided the healthy development of science and technology finance by means of determining the pilot investment to set up a government-led science and technology finance platform since the beginning of the development of science and technology finance, and now it has developed a market-oriented science and technology finance platform because of the artificial intelligence in the market. Block-chain technology, big data and the Internet in the application of science and technology finance innovation came into being; all of these rely on the support of the government. 
However, the financial science and technology market also appears a lot and miscellaneous in the rapid development of science and technology, the industry level is uneven, difficult to manage and so on. Because the entry threshold standard is different, and the related system still needs to be perfected, plus the supervision is not in place, the development in the industry is not balanced, and the science and technology finance environment needs to be improved. Secondly, our country has insufficient investment in $\mathrm{R}$ \& $\mathrm{D}$. In 2014, the expenditure on research and experimental development in our country accounted for less than 2\% of GDP. Moreover, some enterprises in our country do not attach importance to the long-term benefits of scientific research, do not want to have a long period of income and invest a large amount of funds. High-risk projects have too much investment and focus on controlling immediate costs.

\subsection{Future development trend of science and technology finance}

Technology, finance and innovation are closely combined. Foothold is science and technology, the fundamental purpose is to stimulate economic development, convenient for the people. The renewal of the technology and finance industry is very fast and requires a keen sense of business to grasp the pain point of consumption, to break through and innovate to meet the needs of the public. Artificial intelligence, block chain, big data and cloud computing technology will play an important role in the future development of science and technology finance. It provides platform and technical support for the development of science and technology finance, and provides more accurate data analysis for financial investment management activities. The multi-level capital market was further improved. Investors and financiers will have a more diversified demand for investment and financing services. Under the influence of the government and the market, they will put more emphasis on indirect financing, less on direct financing, more on bank financing, less on financial investment in the securities market, more on the stock market, less on the bond market, and more on national debt, The problem of light-enterprise debt will be further solved, market risks will be effectively dispersed, and the structure of capital allocation will be more rationalized.

\section{The existing coordinated development pattern of regional science technology finance}

\subsection{The United States model of synergy innovation science and technology finance}

The American model is a typical market-oriented innovation model of science and technology and finance. A number of new enterprises emerged in the United States As early as the 1940s. The new technologies and products developed by these enterprises have a great impact on a new round of economic growth in the United States. However, the scale of these enterprises is generally small, products and markets are not yet mature because they are in their infancy. The U.S. government quickly recognized this and took a series of measures to protect and support these small and medium-sized technology enterprises. At the same time, in order to effectively reduce the market risk of start-ups, the U.S. government also provides a market for them through government procurement, to establish policy-oriented financial institutions and the opening up of the venture capital market, such as the establishment and development of the NASDAQ market, can be said to be the most typical examples of collaborative innovation between science and technology finance. Its establishment has promoted the combination of financial capital and high technology, which has created a large number of high-growth enterprises.

\subsection{Japanese model of synergetic innovation science and technology finance}

Japanese model is a typical government-led innovation model of science and technology finance. The legislation system of small and medium-sized enterprises includes basic law, single regulation, organic law, promotion law and behavior law, and all kinds of laws and regulations complement each other to form a complete legislation system of small and medium-sized enterprises in Japan. At the same time, the Japanese government also from tax incentives and financial subsidies two aspects, to give strong support to small and medium-sized enterprises. In terms of the financial system, Japan has innovated and introduced a financial system with public finance as its central 
position. In other words, in the process of the flow of funds from suppliers to financiers, a considerable part of the financial system has to go through government financial institutions. Government financial institutions then arrange the flow of funds according to the government's intention. There are so many policy-oriented financial institutions in Japan. At present, the contribution of policy-oriented financial institutions in the financing of small and medium-sized enterprises is about 10 percent. The Japanese government attaches great importance to the financing of SMEs and establishes a credit guarantee system for SMEs. In addition, the Japanese government also set up a series of credit guarantee policy financial institutions. Venture capital firms, such as those set up by the Ministry of Labor, are institutions that guarantee technology loans from commercial banks. After that, the Japanese government also set up the "Research and Development Enterprise cultivation Center" and the non-profit fund "venture enterprise center (VEC)" to provide loan guarantee for technology enterprises and venture enterprises, respectively.

\subsection{The enlightenment of the comparative analysis between the United States and Japan on China}

Through the comparative analysis of the experiences of American and Japanese science and technology financial integration, the enlightenment to Chinese science and technology finance work can be obtained.

First, the integration of technology and finance should be adapted to the national conditions of a country. Different countries have different levels of economic development, financial system perfection, market development and historical and cultural background.

Second, policy finance can play a supporting and leading role in the integration of science and technology finance. Both the United States with developed capital markets and Japan with strong banking and financial institutions attach great importance to the role of policy finance in supporting and guiding small and medium-sized enterprises. Under the guidance of policy finance, a large amount of social idle funds flow to science and technology innovation, especially to small and medium-sized scientific and technological enterprises, which plays an important role in the development of science and technology and economy of a country.

Third, the active participation of commercial banks can well promote the integration of technology and finance. From Japan's experience, in the process of developing a "bank-oriented" financial system, there is also a lack of support and attention to small and medium-sized enterprises by large financial institutions. However, through the establishment of a large number of small and medium-sized financial institutions, Japan has solved the problem of financing difficulties for small and medium-sized enterprises, thus forming a dual docking mode of "large banks supporting large enterprises' scientific and technological innovation and small and medium-sized financial institutions supporting small and medium-sized enterprises' scientific and technological innovation".

Fourth, the perfect credit guarantee system can amplify the financial support science and technology innovation effect and the strength. The combination of science and finance cannot leave the perfect credit guarantee system. The credit guarantee system reduces the loan risk of the bank, promotes the bank to the small and medium-sized enterprise financing, and effectively exerts the function. The guarantee system of small and medium-sized enterprises in the United States and Japan has many similarities in legal system perfection, guarantee fund funded by the government, construction of multi-level system, risk control management and so on, but there are some differences between them.

Fifth, the developed capital market and venture capital market can accelerate the integration of science and technology finance. The United States has the most developed capital market and venture capital market in the world, and has formed an effective linkage mechanism with the scientific and technological innovation activities, which has greatly promoted the scientific and technological progress and sustainable economic development of the United States. In contrast, the capital market and venture capital market in Japan are not perfect, and they have not fully played the basic role of financial market and the function of resource allocation. Japanese financial 
institutions and large enterprises constitute the main source of venture capital, which to some extent limits the support for high-tech industries.

\section{Coordinated development strategy of regional science and technology finance}

The coordinated development strategy of regional science and technology finance can be divided into two directions, one is external strategy, the other is internal strategy. The so-called external strategy refers to the national government, commercial banks and other policies or projects favorable to the financing of emerging technology enterprises, while internal policies refer to the strategies made by the enterprises themselves to increase financing.

\subsection{To create external environment strategy}

\subsubsection{State supporting policy for the development of emerging science and technology enterprises}

The role of government is very important from the international experience of the development of science and technology finance in innovative countries. The role of the government mainly includes: establishing and perfecting the laws and regulations related to science and technology finance, forming a legal environment conducive to financial support for scientific and technological innovation, setting up policy-oriented scientific and technological banks to provide strong policy-oriented financial support, establish and improve the credit guarantee system for science and technology enterprises, support venture enterprises, promote venture capital and develop and activate the venture capital market, establish and improve multi-level capital markets to encourage scientific and technological enterprises to list overseas, to broaden the financing channels of enterprises, promote the integration of industry, education and research, and foster the mode of "Science and Technology Finance Park ". The practice of the governments of innovative countries such as the United States, Germany, Japan and Israel in the field of science and technology finance has achieved varying degrees of success in promoting the development of science and technology finance in their own countries and thus promoting the development of science and technology innovation.

\subsubsection{Establishment an information exchange platform}

Investors cannot see new things, emerging technology companies cannot find investors. This is a common phenomenon of information asymmetry in the process of technological innovation, and also one of the main reasons for the bad development of science and technology finance industry. It is necessary to build a direct investment and financing platform, and the government led by the formation of an effective regulatory mechanism, closely linked to the status quo of the market, to strengthen the effective information exchange between investment and financing, which is the effect of improving the efficiency of investment and financing of science and technology through direct investment and financing platform, to expand the sources of financing for new science and technology enterprises, strengthen the matching degree between investment and financing, at the same time, government should have intervention in control and supervision, effective control of both sides of the enterprise risk.

\subsection{To optimize the internal environment of the enterprise strategy}

New science and technology enterprises need to grow up, the support of government is external force, and the maturity and development of enterprises themselves are internal forces, both of which are indispensable for the development of new enterprises. Of these two, the growth of the enterprise itself is more important.

\subsubsection{To enhance the technological content of the enterprise}

Both national policies and private financial institutions are outside help, emerging technology companies want to develop to get more financing, more need their own strong. Enterprises need their own irreplaceable technology or products 。 


\subsubsection{To strengthen the human resource management in enterprises}

It is found that such enterprises set up enterprises based on science and technology, taking talents as the core competitiveness, and taking research and development and application as the market breakthrough among the scientific and technological enterprises investigated in recent years, but the internal human resources development and management of enterprises are mostly in blank. In the talent market, this kind of enterprise personnel flow quickly, the sense of belonging is not strong. It is necessary to establish the specialized human resources department to introduce professional human resources talents, and build the enterprise scientific human resources management system, and systematically rectify the existing talents and establish an objective and fair performance system, improve the compensation and incentive mechanism of the enterprise, strengthen the connotation of the enterprise, strengthen the enterprise culture advocacy, and strengthen the sense of belonging of the employees.

\section{Conclusion}

All in all, the construction of an innovative country means that our scientific and technological innovation should continue to make a major breakthrough and keep at the advanced level of the world. This requires the nation to carry out top-level design and further promote relevant institutional and institutional reforms to continuously advance major scientific and technological challenges, while also building on the growth of the country's overall innovative power and broad innovation activities, developing science and technology finance is the only way.

\section{Acknowledgments}

Fund Project: This article was funded by Xi'an Peihua College-level Scientific Research Project. Project Name: Regional Science and Technology Finance Collaborative Development Strategy Research; Project No.: PHKT18051

\section{References}

[1] Yue Xu. On the Cooperative Development Model of Regional Science and Technology Innovation and Finance [J]. Operator, 2014 (3): 60-60

[2] Ying Jiang, Hongbo Yang. On the Current Situation of Science and Technology Finance and its Countermeasures in China [J]. Journal of Shanghai Lixin Institute of Accounting and Finance, 2018 (1): 83-95

[3] Yuanyuan Zhang, Wenqiang Yuan, Donghuang Liu, et al. On Cooperative Development of Regional Science and Technology Innovation and Science and Technology Finance: An Analysis Based on Coupling System Theory [J]. Technical economy and Management Research, 2017 (6): 71-76.

[4] Mingying Wang. Measurement and Promotion of Synergetic Development of Science and Technology Finance and Innovation in China [J]. Exploration of Financial Theory, 2017 (1): 68-75.

[5] Mengjie Guo. On the Current Situation and Countermeasures of the Coordinated Development of Science and Technology Finance in Beijing, Tianjin and Hebei [J]. Chinese Coal Industry, 2017 (9): 70-72.

[6] Mingyan Sun. On the Development of Strategic Emerging Industry supported by Science and Technology Finance in China [J]. Innovation and Technology, 2017 (2): 67-69. 